\title{
Verapamil in primary pulmonary hypertension
}

\author{
IVAN MALČIC, DARKO RICHTER \\ From the University Children's Hospital Salata, Zagreb University, Zagreb, Yugoslavia
}

SUMMARY An 8 year old girl with primary pulmonary hypertension and signs of heart failure was given $17.5 \mathrm{mg}$ of verapamil injected into the pulmonary artery over 25 minutes to test for the reversibility of pulmonary arteriolar obstruction. Pulmonary artery pressure fell from 70/50 to $35 / 25 \mathrm{~mm} \mathrm{Hg}$. Treatment with $40 \mathrm{mg}$ verapamil by mouth four times daily was started, and she was discharged. She gradually became asymptomatic and resumed the activities of a normal child of school age. On recatheterisation seven months later her pulmonary artery pressure was 30/ $10 \mathrm{~mm} \mathrm{Hg}$. She was still doing well 12 months after the start of treatment.

Primary pulmonary hypertension has a poor prognosis and is a frustrating problem for the managing physician. Calcium antagonists have smooth muscle relaxing properties ${ }^{1}$ and well known systemic vasodilator and antihypertensive effects. ${ }^{2}$ McMurtry $e t$ al showed on a rat lung model that calcium antagonists were capable of inhibiting the hypoxic pulmonary vasoconstriction response. ${ }^{3}$ Patients with primary pulmonary hypertension have subsequently been treated with these agents with varying degrees of success.

\section{Case report}

An 8 year old girl was admitted for investigation of palpitation, chest pain, progressive breathlessness, and fatigue. The symptoms had appeared and worsened during the preceding year. On examination she was slightly tachypnoeic and cyanotic. Her weight was $27.4 \mathrm{~kg}$, height $137 \mathrm{~cm}$. There was a left precordial lift and a clearly palpable second heart sound over the base of the heart. A grade $2 / 6$ mid systolic murmur, an early diastolic murmur, and the booming and split second heart sound could be heard in the pulmonary area. Radiographs indicated an enlarged heart shadow with prominent proximal pulmonary vascular markings tapering sharply in the periphery. Electrocardiography (Fig. 1) showed right axis deviation $\left(+130^{\circ}\right)$, right atrial and right ventricular hypertrophy, and the right ventricular strain pattern. Echocardiography showed evidence of an enlarged $(2 \mathrm{~cm})$ and highly trabeculated right ventricle, thick-

Requests for reprints to Dr Darko Richter, Gajeva 36, 41000 Zagreb, Yugoslavia.
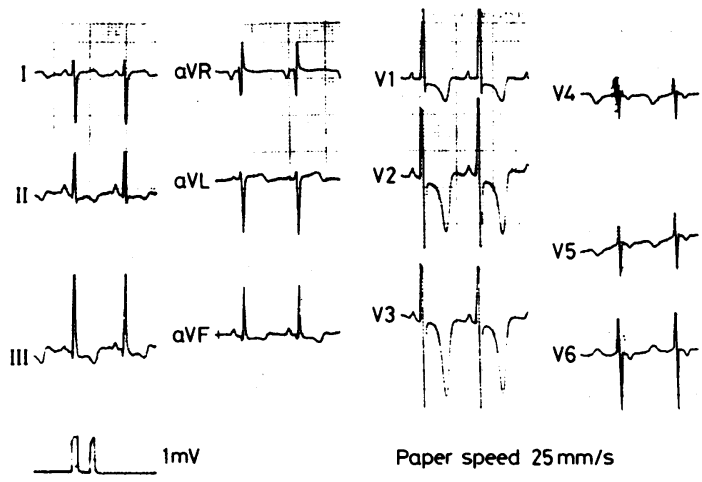

Fig. 1 Electrocardiograms before treatment. The tall and peaked $P$ wave in leads II and V2 is characteristic of right atrial enlargement. The electrical axis is deviated to the right. The signs of right ventricular hypertrophy are accompanied by inverted and deep $T$ waves in $V 2$ and $V 3$ and $S T$ segment depression in VI to $V 3$ indicating right ventricular strain.

ening of the interventricular septum $(1.5 \mathrm{~cm})$, and a dilated right ventricular outflow tract. The two branches of the main pulmonary artery were widened; the right one appeared to be wider than the aorta. The pulmonary valve produced a very shallow " $a$ " wave, a partial systolic closure, and a horizontal diastolic echo movement. Radiocardiography did not show any signs of intracardiac shunting. The liver was palpable $3 \mathrm{~cm}$ below the right costal margin. The neck veins were distended. We could not elicit a history suggesting any kind of peripheral thrombosis or pulmonary thromboembolism.

During catheterisation she had raised right ventricular and pulmonary artery pressures. The mean 
Table Haemodynamic data obtained at catheterisation before treatment and immediately after injecting verapamil into the pulmonary artery and at recatheterisation after seven months' oral treatment with verapamil

\begin{tabular}{|c|c|c|c|}
\hline & Before treatment & $\begin{array}{l}\text { Immediately after } \\
\text { injection of verapamil }\end{array}$ & $\begin{array}{l}\text { After seven months' } \\
\text { oral verapamil }\end{array}$ \\
\hline $\begin{array}{l}\text { Pulmonary artery pressure }(\mathrm{mm} \mathrm{Hg}) \\
\text { Pulmonary vascular resistance }\left(\mathrm{dyn} \mathrm{s} \mathrm{cm}^{-5}\right) \\
\text { Cardiac index }\left(1 / \text { min per } \mathrm{m}^{2}\right) \\
\text { Mean right atrial pressure }(\mathrm{mm} \mathrm{Hg}) \\
\text { Right ventricular }\end{array}$ & $\begin{array}{c}70 / 50 \\
607 \cdot 9 \\
3 \cdot 29 \\
8\end{array}$ & $\begin{array}{c}35 / 25 \\
364.7 \\
3.29\end{array}$ & $\begin{array}{c}30 / 10 \\
226 \cdot 4 \\
4 \cdot 42 \\
4\end{array}$ \\
\hline $\begin{array}{l}\text { Right ventricular systolic/end diastolic } \\
\text { pressure (mm Hg) } \\
\text { Heart rate (beats/min) } \\
\text { Systemic blood pressure (mm } \mathrm{Hg})\end{array}$ & $\begin{array}{l}55 / 10 \\
110 \\
110 / 65\end{array}$ & $\begin{array}{l}40 / 10 \\
70 \\
95 / 60\end{array}$ & $\begin{array}{c}25 / 0 \\
80 \\
100 / 60\end{array}$ \\
\hline
\end{tabular}

Conversion- $\mathrm{kPa}=\mathrm{mm} \mathrm{Hg} / 7 \cdot 5$.

pulmonary artery wedge pressure was $15 \mathrm{~mm} \mathrm{Hg}$ $(2 \mathrm{kPa})$. A total of $17.5 \mathrm{mg}$ verapamil was given over 25 minutes $(2.5,2.5,2.5,5.0$, and $5.0 \mathrm{mg}$ at five minute intervals) into the pulmonary artery with prompt improvement in the haemodynamic indices (Table).

After catheterisation she was given $40 \mathrm{mg}$ verapamil by mouth four times daily. Over the next few months she became asymptomatic and resumed her normal activities, which included walking $7 \mathrm{~km}$ daily. Seven months later she was admitted for recatheterisation. She had no subjective symptoms, cyanosis, or precordial lift, and the second heart sound was no longer palpable. The diastolic murmur had disappeared, the systolic murmur was of grade $1 / 6$, and the second heart sound was slightly accentuated. Radiographs showed the heart shadow to be of normal size, the pulmonary artery to be slightly prominent, and peripheral pulmonary vascular markings to be normal. The electrocardiogram did not show any evidence of right atrial hypertrophy or right ventricular strain pattern, the heart axis was $+95^{\circ}$, and the right ventricular hypertrophy was appreciably improved (Fig. 2). Residual echocardiographic abnormalities

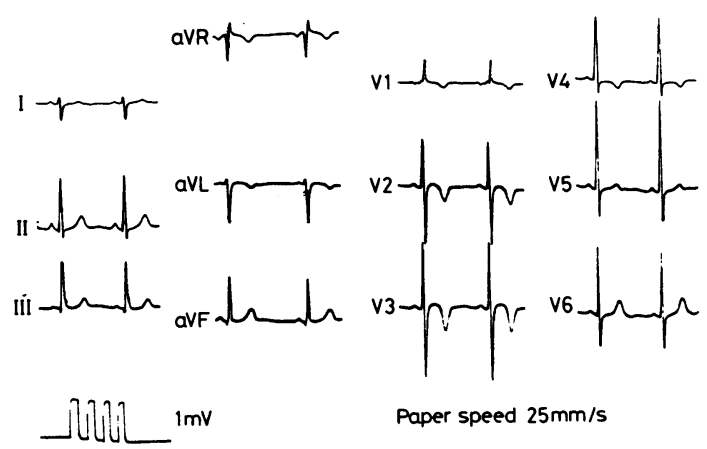

Fig. 2 Electrocardiograms after seven months' treatment with verapamil. The $P$ wave is now normal and the electrical axis nearly vertical. Signs of right ventricular hypertrophy have improved, and the ST segment has returned to the baseline indicating the disappearance of the right ventricular strain. included an enlarged right ventricle, dilated pulmonary artery branches, and thickening of the interventricular septum. The liver was not palpable below the costal margin. The Table shows the pressures and haemodynamic values obtained on recatheterisation.

The dose of verapamil was changed to $60 \mathrm{mg}$ by mouth three times daily, and she was discharged. Twelve months after the start of the treatment she was still undergoing regular check ups and was doing well clinically, according to electrocardiographic and radiographic findings. No untoward side effects of the drug were seen throughout the treatment.

\section{Discussion}

Our patient presented with a typical picture of comparatively rapidly developing primary pulmonary hypertension. Her pulmonary artery pressure and pulmonary vascular resistance were noticeably increased. The cardiac index was not, however, appreciably depressed. This feature may be seen in early primary pulmonary hypertension and has been found in other patients. ${ }^{4}$ On administering verapamil into the pulmonary artery we observed prompt haemodynamic improvement which was sustained throughout long term oral treatment. On recatheterisation her cardiac index was increased and the pulmonary artery pressure and pulmonary vascular resistance were virtually normal.

One young woman has been reported to have experienced similar clinical and haemodynamic improvement when treated with nifedipine, another calcium blocking agent. ${ }^{4}$ She was followed up for six months. Two other young women have been reported to have gained appreciable clinical benefit from treatment with nifedipine. ${ }^{56}$ The fall in their respective pulmonary artery pressures was not, however, impressive, and the pulmonary vascular resistances remained above expected normal values. Their cardiac outputs were also increased. They were followed up for three and four months respectively. Similar clinical and haemodynamic effects have been reported in a young woman treated with diltiazem and followed 
up for 11 months. ${ }^{7}$

Another young woman has been reported to have had a precipitous fall in pulmonary artery pressure after $20 \mathrm{mg}$ nifedipine, but the effect could not be sustained for longer than three hours despite the administration of additional nifedipine. ${ }^{8}$ Farber $e t$ al reported death 54 hours after starting nifedipine in a 63 year old man with pulmonary hypertension secondary to a long standing sarcoidosis but could not relate it clearly to the drug. 9

It is not clear why certain patients with primary pulmonary hypertension show remarkable improvement when treated with calcium blocking agents while others improve less or not at all. The one obvious prerequisite for success is the absence of the fixed anatomical obstruction of the pulmonary arterioles. Some authors claim that the improvement is consequent on increased cardiac output rather than on a decrease in pulmonary artery pressure, which in certain patients is only modest. ${ }^{10}$ Until we obtain reliable data from controlled clinical trials all individual cases must be reported thoroughly, both successes and failures, to define more factors that might influence the chances of successful treatment.

\section{References}

1 Van Breemen C, Mangel A, Fahim M, Meisheri $\mathrm{K}$.
Selectivity of calcium antagonistic action in vascular smooth muscle. Am $\mathcal{F}$ Cardiol 1982; 49: 507-10.

2 Guazzi M, Olivari MT, Polese A, Fiorentini C, Magrini F, Moruzzi P. Nifedipine, a new antihypertensive with rapid action. Clin Pharmacol Ther 1977; 22: 528-32.

3 McMurtry IF, Davidson AB, Reeves JT, Grover RF. Inhibition of hypoxic pulmonary vasoconstriction by calcium antagonists in isolated rat lungs. Circ Res 1976; 38: 99-104.

4 De Freyter PJ, Kerkkamp HJJ, de Jong JP. Sustained beneficial effect of nifedipine in primary pulmonary hypertension. Am Heart f 1983; 105: 333-4.

5 Camerini F, Alberti E, Klugmann S, Salvi A. Primary pulmonary hypertension: effects of nifedipine. $\mathrm{Br}$ Heart f 1980; 44: 352-6.

6 Wise JR Jr. Nifedipine in the treatment of primary pulmonary hypertension. Am Heart f 1983; 105: 693-4.

7 Kambara H, Fujimoto K, Wakabayashi A, Kawai C. Primary pulmonary hypertension: beneficial therapy with diltiazem. Am Heart $\mathcal{f}$ 1981; 101: 230-1.

8 Wood BA, Tortoledo F, Luck JC, Fennell WH. Rapid attenuation of response to nifedipine in primary pulmonary hypertension. Chest 1982; 82: 793-4.

9 Farber HW, Karlinsky JB, Faling LJ. Fatal outcome following nifedipine for pulmonary hypertension. Chest 1983; 83: 708-9.

10 Mélot C, Naeije R, Mols P, Vandenbossche J-L, Denolin $H$. Effects of nifedipine on ventilation/perfusion matching in primary pulmonary hypertension. Chest 1983; 83: 203-7. 